\title{
THE ROLE OF YOGA THERAPY IN THE MANAGEMENT OF BRONCHIAL ASTHMA (TAMAKA SHWASA)
}

\section{ARPAN A BHATT ${ }^{1}$, SHWETA PANDEY ${ }^{2 *}$, BRAJESH SINGH ${ }^{3}$, GAURAVI VYAS ${ }^{4}$, GYANENDRA DATTA SHUKLA ${ }^{5}$, UPASNA GULATI ${ }^{2}$}

${ }^{1}$ Swasthvrutta Vibhaga, Gulab Kunwerba Ayurved Mahavidalaya, Gujarat Ayurved University, Jamnagar, Gujarat, India. ${ }^{2}$ Department of Kayachikitsa, Rishikul Campus, Haridwar, (Uttarakhand Ayurveda University, Dehradun), Uttarakhand, India. ${ }^{3}$ Department of Yog, Morarji Desai National Institute of Yoga, New Delhi, India. ${ }^{4}$ Department of Yog, Maharashi Patanjali Institute of Yoga and Naturopathy Education and Research, Gujarat Ayurved University, Jamnagar, Gujarat, India. ${ }^{5}$ Department of Panchakarma, Gurukul Campus, Haridwar, (Uttarkhand Ayurved University, Dehradun), Uttarakhand, India. Email: drshwetans83@gmail.com

Received: 20 August 2019, Revised and Accepted: 01 October 2019

ABSTRACT

Objective: The present study was conducted on patients taken from Swasthavrutta department of Gujarat Ayurved University in Jamnagar town, Gujarat. The study was done with an objective of providing a safe and reliable as well as cost-effective natural management of symptoms occurring in patients of bronchial asthma. This is also done to reduce the various harmful effects of modern medicines among the patients and to reduce the use and dependency on inhalers.

Methods: Thirty-two patients with bronchial asthma (Tamaka Shwasa) underwent training for 16 weeks in an integrated set of yoga exercises, including prayer, strengthening exercises, Yogasanas (including standing Asana, prone Asana, sitting Asana, and supine Asana), Pranayama (Nadi Shodhana, Ujjayi, Bhramari, and Aumkara Dharana), and Shuddhi Kriya (to be done once in a week) which includes Kunjal, Sutraneti, and Kapalabhati. The patients were told to practice these exercises for 60 min daily.

Results: Significant improvement was seen in the patients who undergone yogic interventions. There was significant improvement in the duration of Shwasakashtata, frequency of Shwasakashtata, reduction in taking number of emergency medicine, Pinasa, Kaphashtheevana, cough, Ghurghuraka, orthopnea, Parshvashula, Lalate Sweda, result on peak expiratory flow rate, airway exchange catheters, oxyhemoglobin saturation, and chest expansion.

Conclusion: From the study, it can be concluded that yoga practices can be opted as long-term management of bronchial asthma, but its beneficial effects need to be studied in more details on large sample size.

Keywords: Bronchial asthma, Tamaka Shwasa, Yoga, Pranayama.

(C) 2019 The Authors. Published by Innovare Academic Sciences Pvt Ltd. This is an open access article under the CC BY license (http://creativecommons. org/licenses/by/4. 0/) DOI: http://dx.doi.org/10.22159/ajpcr.2019.v12i12.35407

\section{INTRODUCTION}

Bronchial asthma is one of the chronic inflammatory diseases of the airways. It is commonly associated with an airway hyperresponsiveness which leads to recurrent episodes of wheezing, breathlessness, chest tightness, and coughing mainly at night or in the early morning [1]. Among various etiopathogenic features of asthma, increased vagal tone is one among them [2]. According to the Global Asthma Report (2014), asthma symptoms such as breathlessness usually lead to the feeling of fear, emotional, and psychological suffering in asthma patients. The stigma associated with the diagnosis of asthma is among the major obstacles in course of better asthma management [3]. Yoga and Pranayam practices adjust the autonomic imbalance, control the rate of breathing, and thus alter various physiological variables. They also have their impact on the psychological status of the asthmatic patient and help in reducing the stigma associated. These changes are mainly due to decreased sympathetic reactivity and relaxation of voluntary inspiratory and expiratory muscles [4]. Various studies have been conducted on the effect of breathing techniques in asthma. Various scholars have reported improvement in asthmatic patients with the use of various yogic breathing exercises [5-7]. With the aim of improving the quality of life of asthmatic patients by intervening them into various yoga practices, the present study was conducted.

\section{METHODS}

The study was conducted at the Swasthavrutta department of Gujarat Ayurved University in Jamnagar town, Gujarat. A clinical trial, controlled prospective study was conducted on 32 patients by intervening into yoga practice everyday for $60 \mathrm{~min}$ for 16 weeks by a yoga trainer. of 32 patients, 30 completed the trial and 2 left against medical advice.

The yoga practice includes:

1. Prayer $5.0 \mathrm{~min}$

2. Strengthening exercises (sakti vikasaka $10 \mathrm{~min}$

suksma vyayama)

Greeva Shakti Vikasaka Prathama, 5 rounds

Dwitiya, Trutiya

Vakshasthala Shakti Vikasaka 5 rounds

Prathama, Dwitiya

Udara Shakti Vikasaka Prathama, 5 rounds

Dwitiya, Trutiya

3. Yogasanas

Standing Asanas:

Tadasana, Urdhva hastottanasana,

Ardha Chakrasana, Katichakrasana

Prone Asanas

Bhujangasana, Dhanurasana

Sitting Asanas

Ushtrasana, Shashankasana,

Uttanamandukasana Gomukhasana

Ardha Matsyendrasana/Vakrasana

Kapalabhati 


\begin{tabular}{|c|c|c|}
\hline & Supine Asanas & $5.0 \mathrm{~min}$ \\
\hline & Uttanpadasana, Ardhahalasana, & \\
\hline & Viparita Karani/Halasana, Setu & \\
\hline & Bandha Sarvangasana, Matsyasana, & \\
\hline & Shavasana & \\
\hline 4. & Pranayama & $15 \mathrm{~min}$ \\
\hline & Nadi Shodhana, Ujaayi, Bhramari, & \\
\hline & Aumkara Dharana & \\
\hline 5. & $\begin{array}{l}\text { Shuddhi Kriya: (to be done once in a } \\
\text { week) Kunjal, Sutraneti, Kapalabhati }\end{array}$ & \\
\hline & Total duration & $60 \mathrm{~min}$ \\
\hline
\end{tabular}

\section{Inclusion criteria}

- Belonging to the age group of 24-60 years

- Had the sign and symptoms of bronchial asthma (Tamaka Shwasa) as given below:

- Shwasa Kashtata - Breathlessness

- Kasa-Coughing

- Parshvashula - Pain in flanks

- Ghurghurakam - Wheezing

- Feeling of chest tightness/compression

- Uncomplicated cases of bronchial asthma

- Chronicity $<10$ years

- Willing and able to participate as well as understanding and affirming to sign written consent for the treatment schedule of the concerned study.

\section{Exclusion criteria}

Patients falling under the following criteria were excluded from the study:

- Age below 24 years and above 60 years

- Patients who were had thrombosis, stroke, and other severe abnormalities such as cardiac disease, renal disorders, acquired immunodeficiency syndrome, endocrine disorders such as diabetes mellitus, thyroidism, etc.

- Patients who had other complicated respiratory diseases, i.e., swine flu, tuberculosis, chronic obstructive pulmonary disease, etc., and had any organic lesion such as tumor or any anatomical defect in the airways were excluded from the study.

The study was approved by Scientific Committee of ACYER and the Ethical Committee of University, and according to the Guidelines of Morarji Desai National Institute of Yoga, some changes were being incorporated.

Participants were given information about the study objective, voluntary participation, and were told about their treatment. They were also told about the activities that were going to be practiced and were also informed as they could withdraw from participation at any stage. Those patients who had signed the consent form participated in the study.

\section{Statistical methods}

Paired " $\mathrm{t}$ " test was used for the subjective and objective parameters.

\section{RESULTS}

Thirty-two patients who fulfilled the inclusion criteria and signed the consent were taken for the study. As 30 patients completed the trial, so, observation of 32 patients and the results of 30 patient's statistical analysis are given below.

Most of the patients in the study showed a decreased number of day attacks per week and night attacks per month $(p<0.05)$. The mean change in the peak expiratory flow rate (PEFR) was 0.52 which was statistically significant $(p<0.05)$. The mean change in the asthma control questionnaire was 6.56 which was statistically significant $(\mathrm{p}<0.001)$. Similar pattern was also observed in the mean change of pulse oximetry, chest expansion, absolute eosinophil count, and other symptoms $(\mathrm{p}<0.001)$.

\section{DISCUSSION}

In the observations of 32 patients of Tamaka Shwasa, maximum number of patients, i.e., $31.25 \%$, were belonging to the age group of 31-40 years and $51-60$ years, $56.25 \%$ were of male sex, and $40.62 \%$ patients were housewives.

This study showed a reduction in the number of asthma attacks which is comparable to the previous research work $[7,8]$.

The improvement in PEFR in this study is also comparable to the previous studies [7].

This explains the effect of yoga in the relief of asthma attack and improves the quality of life. The responsiveness of air ways is noticeably increased in asthma patients so that they develop bronchoconstrictions for smaller amount of physicochemical stimuli than the healthy ones. There is a complex interplay of several factors, namely inherent responsiveness of smooth muscles, abnormality in autonomic nervous control, and breakdown in airway defence may promote bronchial hyper reactivity. Hence, reducing the hyperresponsiveness of the patients will benefit them to have good outcome in the control of their asthma.

The other way is the psychological effect on asthma progression, though the mechanism is complex and not well understood; still psychological factors affect about half of all patients. This was the focus pointed to be improved by the yoga exercise and showed improvement in different studies [7].

\section{Mode of action of various yoga practices}

- Greeva Shakti Vikasaka Prathama, Dwitiya, and Trutiya as shown in Fig. 1 increase vitality and improve sleep, vision, and hearing. This will help to remove excessive Kapha from the upper part, as it is the seat of Kapha. Increased blood circulation and nervous supply will help to relax constricted bronchial tubes, thus patients get relief by this Kriya. This Kriya corrects the energy flow to Vishuddhi Chakra which improves Akashtatva balance and congestion of lungs, thus helpful in bronchial asthma.

- Vakshasthala Shakti Vikasaka Prathama, Dwitiya, and Trutiya as shown in Fig. 1 strengthen chest muscles. Due to chest expansion, the lungs will fill with sufficient amount of air. Increased lungs capacity will help to cure bronchial asthma by more oxygenated air flow to system. Anahat Chakra gets sufficient pranic flow, which channelizes Vayu and removes congestion from Nadies of lungs, thus helpful in bronchial asthma.

- Udara Shakti Vikasaka as shown in Fig. 1 strengthens the abdominal muscles, helps to decrease abdominal fat, and helps to remove diseases of abdomen, as well as of respiratory system. Due to weak abdominal muscle, complete breathing cannot take place which affects respiratory system. This Kriya helps to correct the breath by strengthening abdominal muscles. Manipur Chakra is activated by this Kriya. Active pranic flow to Manipur increases Agnitatva, which improves digestion. As per Ayurvedic concept Bronchial Asthma is Pittanubandhi, so balanced Agnitatva balances Pitta in the system and thus helpful in bronchial asthma.

\section{Standing Asanas}

\section{Tadasana}

It improves respiration and promotes balance in the spine which can aid in proper breathing. Prana flows sufficiently in all Chakras due to balanced spine. Congestion of Kapha is also removed by stretching of the entire body because of gravity. It corrects the body posture too. It helps to activate the apex portion of the lungs also, thus helpful in bronchial asthma.

\section{Urdhva hastottanasana}

It improves air exchange in the lungs and thus the overall lung capacity improves. Increases thoracic mobility and helps chest expansion. Aligns the body and corrects the body posture, strengthens waist muscles 


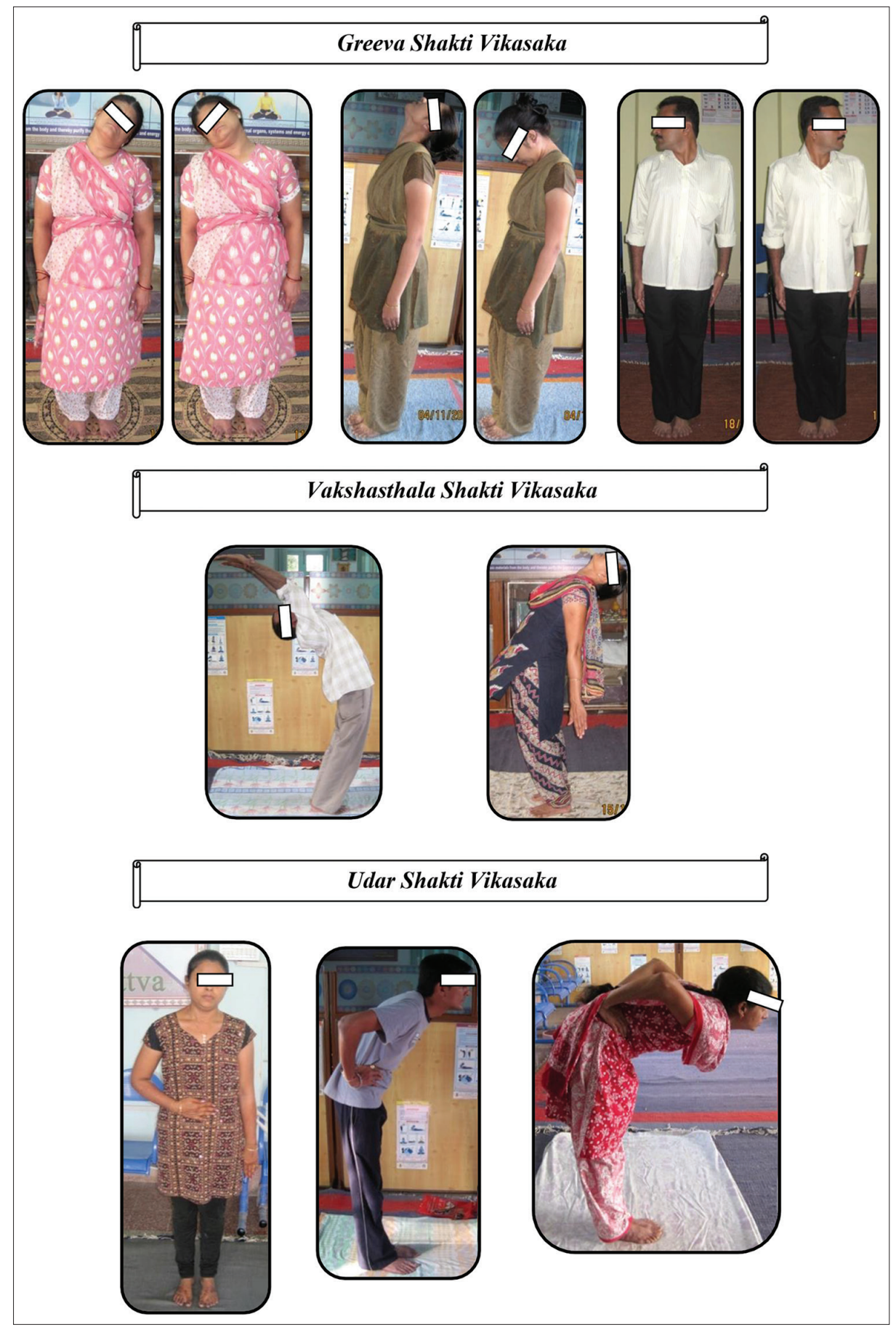

Fig. 1: Strengthening exercises

which improves digestive fire, channelizes Vata, and removes Kapha from Nadis, thus helpful in bronchial asthma.

\section{Ardha Chakrasana}

It strengthens and tones the muscles of the chest, back, and arms. The expansion of the rib cage aids respiration. Spine will be flexible due to backward bending. Prana flows easily from Manipoor Chakra to Vishuddhi Chakra. This Pranic energy will help to channelize the Vata in Nadis of the chest; thus, relaxed bronchioles give relief to the patient, likewise helpful in bronchial asthma.

\section{Katichakrasana}

It gives rotation to thoracic spine and stretches the chest muscles which leads to expansion of the ribcage and improves air exchange in the lungs. Improved respiration helps to remove Kapha from lungs and channelizes Vata, thus helpful in bronchial asthma.

Prone asanas as shown in Fig. 2

Bhujangasana

It stretches the chest, shoulders, and abdomen, firms the buttocks, and stimulates abdominal organs. It also helps to relieve stress and fatigue and helps the heart and lungs to work properly. Lung capacity is enhanced. It stimulates Mooladhara and Swadhishthan Chakra which corrects Vata vitiation and Kapha Dushti by balancing Pruthvi (Earth) and Jala-tatva (water). Abdominal stretching will stimulate Manipura Chakra and corrects Agni Dushti. Anahata and Vishuddhi Chakra are opened by chest expansion, which channelize Vata and increase Aakashatatva thus by balancing Panchtatva helpful to cure bronchial asthma. 


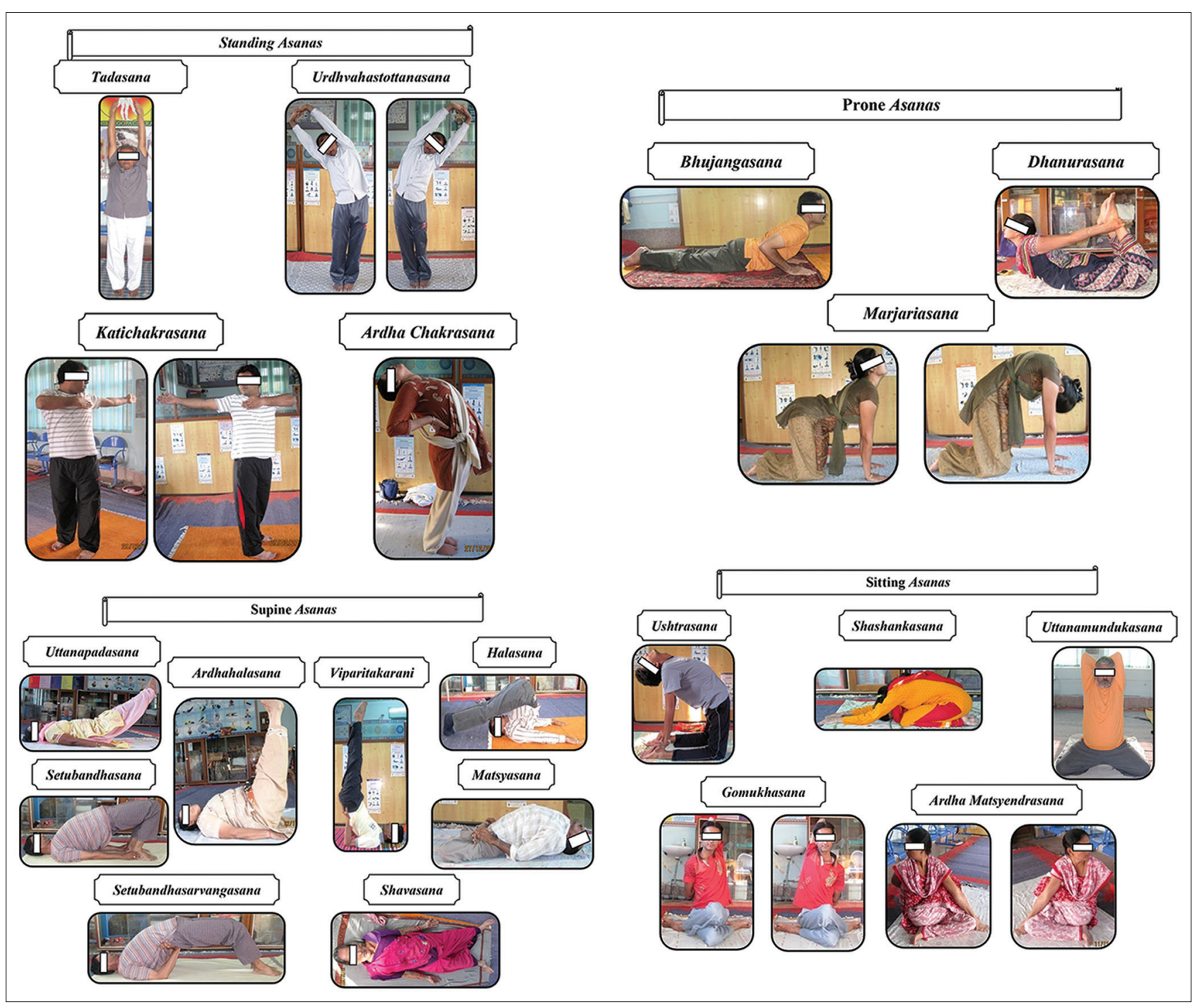

Fig. 2: Yogasanas

\section{Dhanurasana}

It tones up and stimulates the organs of the chest and abdomen. It stretches the chest muscles. Increases circulation to heart and lungs, improves oxygen intake, stretches the diaphragm, and expands the chest region - improves respiratory conditions. Due to spinal curve from top to bottom, each Chakra gets sufficient Pranic flow which removes Kapha and channelizes Vata from Nadis of Vaksha, thus helpful in bronchial asthma.

\section{Marjarasana}

It releases tension from the cervical, thoracic, and lumbar spine and makes lungs stronger. It gives initiate movement from the center and co-ordinate movements and breath. The relaxation of then spine with breathing improves Pranic flow to each Chakra, and correction of breath helps to cure bronchial asthma.

\section{Supine asanas as shown in Fig. 2}

\section{Uttanapadasana}

It bolsters health of digestive organ, lungs, heart, stomach, liver, spleen and intestine counters constipation. Excellent pressure on the abdomen cures Agni Dushti by stimulating Manipoor Chakra and improves digestion which corrects Malayukta Kapha production. A good stretch at the lumbar spine helps to activate Mooladhar Chakra, which relieves constipation and Vata, thus helpful in bronchial asthma.

\section{Ardhahalasana}

Stretching of hamstring and calf muscles and strengthening of lower abdomen improves digestion. Position of legs will increase blood circulation toward the upper part, which provides more nourishment to the chest and lungs. The relaxation of the legs in the final position helps gravity to flow Samana-Vayu easily and diverts Apana-Vayu from the lower extremities. Hence, Vata Prakopa is corrected and asthmatics get relief.

\section{Viparita Karani/Halasana}

It increases the blood flow to the face, neck, and thorax and improves the functioning of adrenal, pituitary, and thyroid glands. This posture diverts Pranic flow to each Chakra. It drains secretions toward main airway path/trachea to be thrown out. This brings balance normalize the functions of Vata and activates Manomayakosha. These will soothen the mind, which is helpful to cure such psychosomatic disorder like B.A.

\section{Setubandhasana}

It strengthens the spine and improves spinal flexibility. Lower back and hip extensor muscles' strengthening improves lumbar curvature and gives stability to lumbosacral etc., improving alignment of LOG. Expansion of the chest improves breathing capacity. This Asana affects Manipoor, Anahat, and Vishuddhi Chakra, which corrects Agni Dushti and channelizes Vata, thus helpful in bronchial asthma. 


\section{Matsyasana}

It stretches the muscles between the ribs (intercostals), makes it more functional, fills the lungs with air, and increases the lung capacity. As the larynx or wind box and trachea (wind-pipe) are thrown open widely, this Asana helps deep breathing. The effect of this Asana is seen in all the Chakras from Muladhar to Vishuddhi. Because of this Asana, all the Nadis i.e Nerves and channels become activated and shuddha (clear and pure). This brings balance and normalizes the function of all Vata and thus helpful in bronchial asthma.

\section{Shavasana}

The posture of this Asana affects the center of gravity, so the front portion of all Chakras is opened and energy balance of the body is improved. As it relaxes the body, Rajas and Tamas are destroyed consciously. The function of all Nadis improved, thus helpful to cure such psychosomatic disorder such as bronchial asthma.

\section{Ushtrasana}

It expands the lungs to their maximum capacity, develops the ribcage, and brings a good effect upon the whole of respiratory system activating the facial tissues, the nasal passage, the pharynx, the lungs, and the whole of respiratory organs and the nerves. Expansion leads to increase ventilation of the alveoli, thus helpful to cure bronchial asthma.

\section{Shashankasana}

It activates the adrenal gland and leads to more adrenaline being secreted when done for a longer duration. This being posture where forward bending is practiced will relax the abdominal muscles, stretch the back muscles, and allow the diaphragm to extend easily downwards; thus, it will help in respiratory problems such as bronchial asthma.

\section{Uttanamandukasana}

It improves the lung potency and circulation in the walls of the chest. Expansion leads to increased ventilation of the alveoli, as it affects Anahat and Vishuddhi Chakra. Prana flows freely in this Chakras due to raised hands in an upward direction, thus helpful to cure bronchial asthma.

\section{Gomukhasana}

It strengthens the muscles of the upper back, upper arms, shoulders, chest, hips, and thighs, improves lung function, and helps to overcome respiratory problems. Expansion of the chest leads to increased air exchange to the basal region of lungs, thus helpful to cure bronchial asthma.

\section{Ardha Matsyendrasana}

It is a great help for the bronchial muscles and rib cage and tones the belly muscles, and therefore, abdominal, respiratory, and cardiovascular organs are also exercised and their functioning improves. As it gives rotation to the thoracic spine and stretches the chest muscles, it leads to the expansion of the ribcage and improves air exchange in the lungs. Prana (Oxygen) flows easily in all Chakras due to spinal curvature and Nadis (Nerves) of front portion are activated and become shuddha which is helpful in bronchial asthma.

\section{Vakrasana}

It is a great help for the bronchial muscles and rib cage. It tones the belly muscles, and therefore, abdominal, respiratory, and cardiovascular organs are also exercised and their functioning improves. As it gives rotation to thoracic spine and stretches the chest muscles, it leads to the expansion of the ribcage and improves air exchange in the lungs, thus helpful in bronchial asthma.

\section{Shuddhi Kriya as shown in Fig. 3}

Kapalabhati

It cleanses the lungs and entire respiratory system by detoxifying them. The blood is purified as well and the body gets an increased supply of

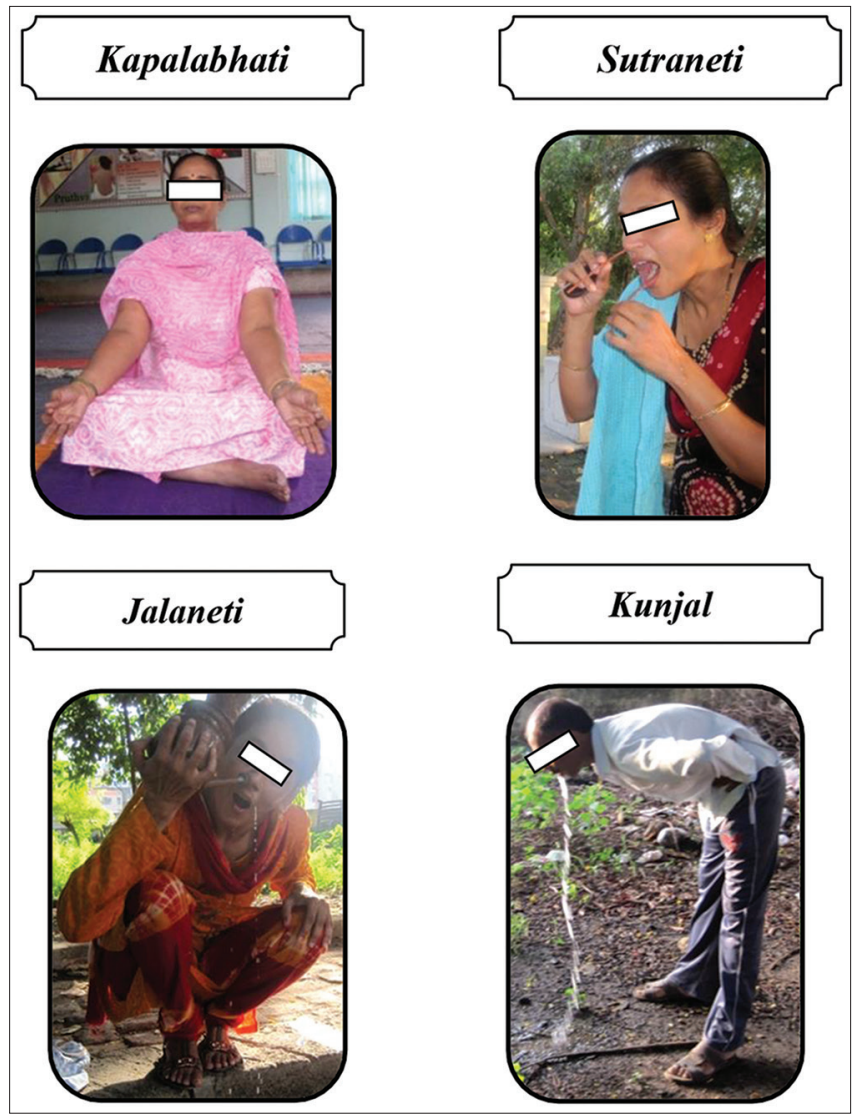

Fig. 3: Shuddhi Kriya

oxygen to all cells. It direct affects on Ajnachakra as suggested by its name Kapalbhati (shines forehead). Due to active abdominal movement, Manipoor Chakra is also activated, which improves the function of Agni. Removal of Kapha channelize the Vata in Nadis (Nerves) and it will help to cure bronchial asthma.

\section{Pranayama as shown in Fig. 4}

Bhastrika

It removes Vata, Pitta, and Kapha from body and increases the body fire. It removes Malayukta Kapha from the lungs easily. Pumping movement of the lungs will increase lung capacity; thus, correction of the entire respiratory system easily cures bronchial asthma.

\section{Nadi Shodhana}

It lowers heart rate and reduces stress and anxiety. It is said to synchronize the two hemispheres of the brain and to purify the subtle energy channels (Nadi) of the body; hence, the Prana flows more easily during Pranayama practice, clears the respiratory passage, and strengthens the lungs.

\section{Ujjayi}

It is most effective for correcting and strengthening the condition of the lungs and the bronchiole linings.

\section{Bhramari}

Concentration on humming sound will calm down and soothes the mind. It relieves mental stress and anxiety. It increases pain tolerance, thus helpful in bronchial asthma.

\section{Aumkara}

This stimulates the secretion of serotonin, nor-epinephrine, and dopamine, thus relieves mental stress and improves the psychoneuroimmune response. The vibration of AUM rapidly relaxes 


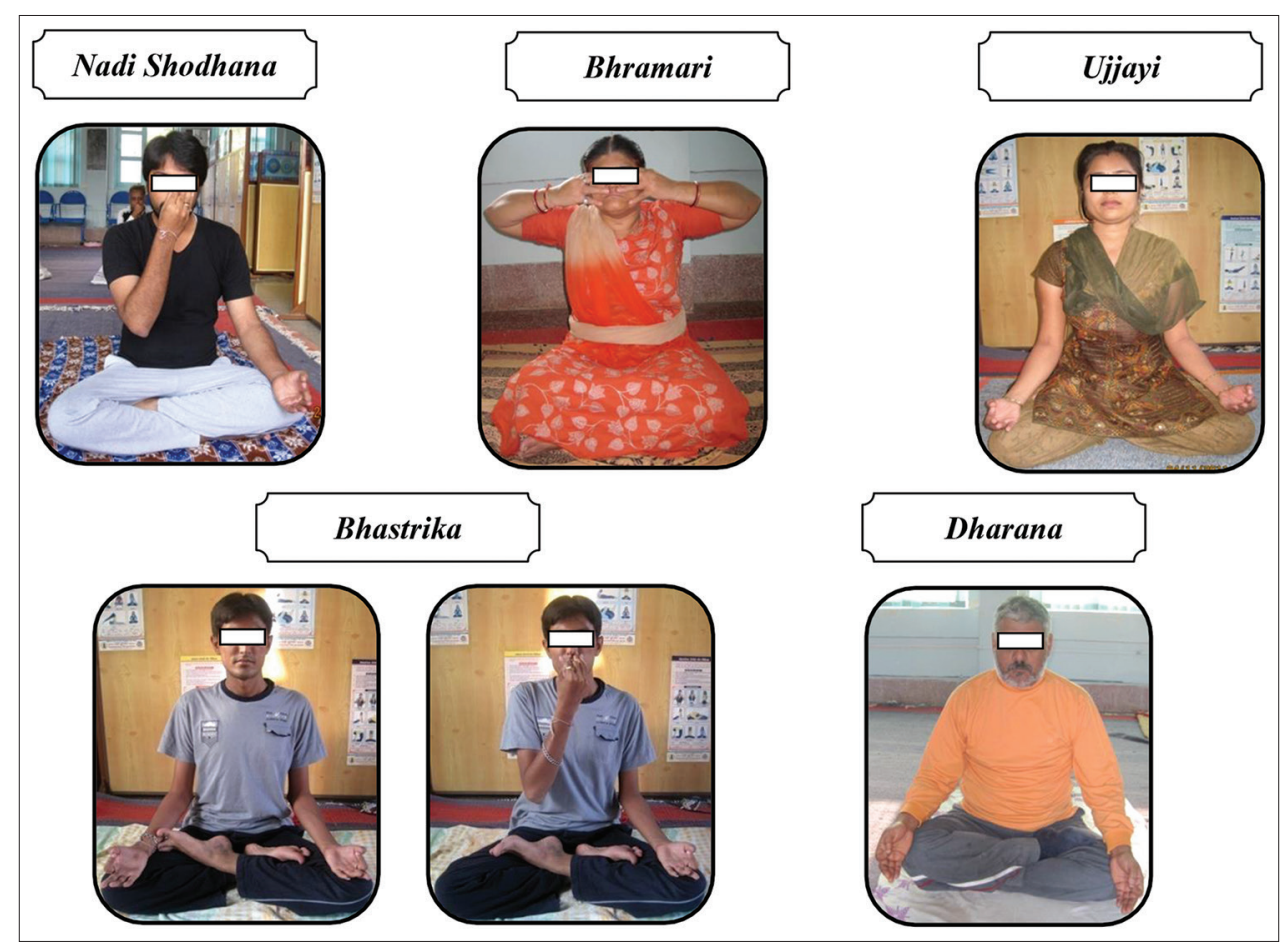

Fig. 4: Pranayama

Table 1: Sociodemographic characteristic of asthmatic patient

\begin{tabular}{ll}
\hline Sociodemographic features & Frequency \\
\hline Sex & \\
Male & 18 \\
Female & 14 \\
Age & \\
$21-30$ & 05 \\
$31-40$ & 10 \\
$41-50$ & 07 \\
$51-60$ & 10 \\
Occupation & \\
Labor & 01 \\
Service & 09 \\
Business & 09 \\
Housewife & 13 \\
\hline
\end{tabular}

Table 2: Mean changes in the subjective and objective parameter before and after the yoga exercise

\begin{tabular}{lll}
\hline Parameters & Mean changes & "p value \\
\hline Shwasakashtata - frequency & 01.66 & $<0.001$ \\
Shwasakashtata - duration of attack & 01.89 & $<0.001$ \\
No. of emergency medicine taken & 01.28 & $<0.001$ \\
Kasa (coughing) & 01.04 & $<0.001$ \\
Kapha Shthivanam (expectoration) & 01.09 & $<0.001$ \\
Ghurghurkam (wheezing) & 01.34 & $<0.001$ \\
Asino Labhate Saukhyam & 01.65 & $<0.001$ \\
Pinasa (rhinitis) & 01.04 & $<0.001$ \\
Chest tightness & 01.37 & $<0.001$ \\
Parshvashula (pain in flanks) & 01.26 & $<0.001$ \\
Lalate Sweda (perspiration on fore head) & 01.68 & $<0.001$ \\
Bhrama (giddiness) & 01.00 & $<0.010$ \\
Peak expiratory flow rate & 00.52 & $<0.050$ \\
(SpO $_{2}$ ) by pulse oximetry & 01.07 & $<0.001$ \\
Absolute eosinophil count & 87.84 & $<0.001$ \\
Chest expansion at the level of nipple & 02.85 & $<0.001$ \\
Asthma control questionnaire & 06.56 & $<0.001$ \\
\hline
\end{tabular}

the mind and body. It quickly brings mental peace and helps to prevent psychosomatic disorder such as bronchial asthma.

\section{Dharana}

This is an excellent method to overcome the problems, conflicts, and other disturbances hidden in the mind and relaxes body - mind too. It increases regenerated capacity of individual. Concentration on Anahata and Vishuddha Chakra along with the Japa-Aum chanting will help to cure such psychosomatic disorder such as bronchial asthma.

\section{Shuddhi Kriyas: (to be done once in a week) as shown in Fig. 3}

Kunjal

It strengthens solar plexus cleanses and stimulates the stomach, esophagus, lungs, chest, heart, throat, nose, eyes, ears, and sinus, and hence, it is very beneficial for asthmatics. The strong contractions made by the pyloric sphincter send a shock wave along the Vagus nerve which can release the spasm within the bronchial tree.

\section{Sutraneti}

It does a frictional massage that strengthens the membranes enabling them to work more efficiently in their function of warming, cleaning, humidifying, and disinfecting the air. Furthermore, the blood supply to the nerves of the air passages is energized enhancing the effects of any subsequent breath work. It excels in removing Catarrh and Kapha. Resistance to infection is improved. It also clears away dried up deposits and foreign bodies by stimulating fluid to help the flushing process. At a more subtle level, Sutraneti stimulates the Ajna Chakra.

\section{Jalaneti}

It helps to remove the mucous filled with dirt and bacteria and drains the nasal passages and sinus cavities. It helps to fight off infections leading to cold and Kapha and other allergy-related problems of the nose and upper respiratory tract such as bronchial asthma.

\section{CONCLUSION}

This study shows that yoga decreases the number of asthma attacks, the use of drugs, and improvement in the peak flow rate. We recommend 
conducting large-scale study on the effect of yoga on asthma. Attempts should be made to instill positivity in asthma patients by communityridden education campaigns to improve the lives of asthma patients, and patients can enjoy their psychosocially active life in the community [3].

\section{CONFLICT OF INTEREST}

None.

\section{REFERENCES}

1. McFadden ER Jr. Disease of the respiratory system-asthma. In: Kasper DL, Braunwald E, Fauci AS, Hauser SL, Longo DL, Jameson JL, editors. Harrison's Principles of Internal Medicine. 16 $6^{\text {th }}$ ed., Vol. 2. New York: McGraw-Hill; 2005. p. 1508-16.

2. Thomas M, McKinley RK, Freeman E, Foy C. Prevalence of dysfunctional breathing in patients treated for asthma in primary care: Cross sectional survey. BMJ 2001;322:1098-100.

3. Ahmad S, Ismail NE. A qualitative study exploring the impact of stigma in the lives of adult asthma patients in Selangor Malaysia. Int J Pharm Pharm Sci 2015;7:975-1491.

4. Ernst E. Breathing techniques adjunctive treatment modalities for asthma? A systematic review. Eur Respir J 2000;15:969-72.

5. Ram FS, Holloway EA, Jones PW. Breathing retraining for asthma. Respir Med 2003;97:501-7.

6. Nagarathna R, Nagendra HR. Yoga for bronchial asthma: A controlled study. Br Med J (Clin Res Ed) 1985;291:1077-9.

7. Singh V, Wisniewski A, Britton J, Tattersfield A. Effect of yoga breathing exercises (pranayama) on airway reactivity in subjects with asthma. Lancet 1990;335:1381-3.

8. Nagendra HR, Nagarathna R. An integrated approach of yoga therapy for bronchial asthma: A 3-54-month prospective study. J Asthma 1986;23:123-37. 